\title{
Correction to: Hierarchical resource scheduling method using improved cuckoo search algorithm for internet of things
}

\section{Chunguang Zhang ${ }^{1} \cdot$ Guangping Zeng ${ }^{1} \cdot$ Hongbo Wang ${ }^{1} \cdot$ Xuyan Tu ${ }^{1}$}

Published online: 20 January 2020

(C) Springer Science+Business Media, LLC, part of Springer Nature 2019

Correction to: Peer-to-Peer Netw. Appl. 2019, 12(6): 1606-1614

https://doi.org/10.1007/s12083-019-00801-8

Correction is needed in the original article.

On page 1606, the affiliation is changed from "University of Technology Science Beijing" to "University of Science and Technology Beijing".

This error also happened five times in the part of authors' bio on page number 1614.

The authors would like to apologise for any inconvenience caused.

Publisher's note Springer Nature remains neutral with regard to jurisdictional claims in published maps and institutional affiliations.

The online version of the original article can be found at https://doi.org/ 10.1007/s12083-019-00801-8

Chunguang Zhang

chunguang_zh@163.com

1 School of Computer \& Communication Engineering, University of Science and Technology Beijing, Beijing 100083, China 